\title{
Antihyperalgesic effects of dexmedetomidine on high-dose remifentanil-induced hyperalgesia
}

\author{
Cheol Lee, Yeon-Dong Kim, and Ji-Na Kim \\ Department of Anesthesiology and Pain Medicine, Wonkwang University College of Medicine, Iksan, Korea
}

Background: Dexmedetomidine is a highly selective $\alpha 2$ adrenergic agonist that has been shown to decrease the intensity of opioid-induced hyperalgesia (OIH). We aimed to investigate the antihyperalgesic effects of dexmedetomidine on high-dose remifentanil-induced hyperalgesia.

Methods: Ninety American Society of Anesthesiologists physical status I-II patients undergoing laparoscopically assisted vaginal hysterectomy (LAVH) were randomly assigned to one of the following three groups, each of which received either dexmedetomidine (an initial dose of $1.0 \mu \mathrm{g} / \mathrm{kg}$ for $10 \mathrm{~min}$, followed by a continuous infusion of $0.7 \mu \mathrm{g} /$ $\mathrm{kg} / \mathrm{hr}$ ) or placebo saline $15 \mathrm{~min}$ before the induction of anesthesia and intraoperative remifentanil infusion: group C received a placebo and $0.05 \mu \mathrm{g} / \mathrm{kg} / \mathrm{min}$ remifentanil; group $\mathrm{RH}$ received a placebo and $0.3 \mu \mathrm{g} / \mathrm{kg} / \mathrm{min}$ remifentanil; and group DRH received dexmedetomidine and $0.3 \mu \mathrm{g} / \mathrm{kg} / \mathrm{min}$ remifentanil.

Results: The mechanical hyperalgesia threshold $24 \mathrm{hr}$ after surgery was significantly lower in group RH than in the other two groups. Postoperative pain intensity using visual analog scale (VAS) and cumulative volume of a patientcontrolled analgesia (PCA) containing morphine over $24 \mathrm{hr}$ were significantly greater in group RH than in group $\mathrm{DRH}$. The time to the first postoperative analgesic requirement was significantly shorter in group RH than in the other two groups. The desflurane requirement was significantly greater in group $\mathrm{C}$ than in the other groups. The frequency of hypotension and bradycardia was significantly higher, but shivering and postoperative nausea and vomiting were significantly lower in group DRH than in the other two groups.

Conclusions: High-doses of remifentanil induced hyperalgesia, which presented a decreased mechanical hyperalgesia threshold, enhanced pain intensity, a shorter time to first postoperative analgesic requirement, and greater morphine consumption, but dexmedetomidine efficiently alleviated those symptoms. Dexmedetomidine may be a novel and effective treatment option for preventing or attenuating OIH. (Korean J Anesthesiol 2013; 64: 301-307)

Key Words: Dexmedetomidine, Opioid-induced hyperalgesia, Remifentanil.

Received: September 12, 2012. Revised: October 5, 2012. Accepted: October 15, 2012.

Corresponding author: Cheol Lee, M.D., Department of Anesthesiology and Pain Medicine, Wonkwang University College of Medicine, 344-2, Sinyong-dong, Iksan 570-711, Korea. Tel: 82-63-859-1564, Fax: 82-63-857-5472, E-mail: ironyii@wku.ac.kr

(c) This is an open-access article distributed under the terms of the Creative Commons Attribution Non-Commercial License (http:// creativecommons.org/licenses/by-nc/3.0/), which permits unrestricted non-commercial use, distribution, and reproduction in any medium, provided the original work is properly cited. 


\section{Introduction}

Dexmedetomidine is a highly selective and potent $\alpha 2$ adrenergic receptor agonist with an $\alpha 1 / \alpha 2$ ratio of $1: 1,620$, comparing with clonidine, which is only a partial agonist with an $\alpha 1 / \alpha 2$ ratio of $1: 220$ [1]. Belgrade and Hall [2] showed that dexmedetomidine could reboot opioid sensitivity in patients with opioid-induced hyperalgesia (OIH) to attenuate pain intensity and lower opioid doses. In addition, dexmedetomidine might contribute to the recovery of normal nociceptive and antinociceptive responses.

Some studies have reported the role of $\alpha 2$ adrenergic receptor agonists in modulating pain sensitivity known as OIH. These studies showed that $\alpha 2$ adrenergic receptor agonists attenuate opioid-induced post-infusion antianalgesia and prevents opioid-induced post-infusion secondary hyperalgesia. These data suggest that $\alpha 2$ adrenergic receptor agonists may play a role in OIH modulation [3-5].

Remifentanil is an ultra-short-acting $\mu$-opioid receptor agonist associated with a predictable and rapid recovery that is independent of the dose and duration of infusion. Its unique pharmacokinetic characteristics make it an effective anesthetic adjuvant, commonly used in general anesthesia [6]. However, considerable evidence suggests that exposure to high-dose remifentanil paradoxically enhances pain sensitivity and increases analgesic requirements [7-9].

In this study, we evaluated the antihyperalgesia effects of a two-step intravenous infusion of dexmedetomidine on highdose remifentanil-induced hyperalgesia, which presented a decreased mechanical hyperalgesia threshold, enhanced pain intensity, a shorter time to first postoperative analgesic requirement, and greater morphine consumption.

\section{Materials and Methods}

We obtained approval from our Institution Review Board and written informed consent from all participants. Ninety (n $=30$ per group) American Society of Anesthesiologists physical status I-II patients aged 20-65 years who were scheduled for laparoscopically assisted vaginal hysterectomy (LAVH) were enrolled in this study. Exclusion criteria included allergy to dexmedetomidine, clinically significant medical or psychiatric conditions, pregnancy, a history of alcohol or drug abuse, or opioid-containing pain or sedative medications.

On the day before surgery, patients were taught how to use the visual analog scale (VAS) and the patient-controlled analgesia (PCA) device. They were instructed to self-deliver analgesia whenever they began to feel pain.

All patients were premedicated with intramuscular midazolam (2-3 $\mathrm{mg}$ ) before arrival in the operating room. The patients were placed on pulse oximeter, automated blood pressure (BP) cuff, electrocardiogram (EKG), and end-tidal $\mathrm{CO}_{2}$ $\left(\mathrm{ETCO}_{2}\right)$ devices. In addition, arterial and urinary catheters were attached as part of the patient's management. Tympanic temperature was measured immediately before induction of anesthesia, and again just before extubation.

The patients were randomly assigned using a computergenerated random number table into one of three treatment groups, each of which received either dexmedetomidine (twostep infusion; an initial dose of $1.0 \mu \mathrm{g} / \mathrm{kg}$ for $10 \mathrm{~min}$, followed by a continuous infusion of $0.7 \mu \mathrm{g} / \mathrm{kg} / \mathrm{h}$ ) or placebo saline 15 min before the induction of anesthesia and intraoperative remifentanil infusion: group $\mathrm{C}$ received a placebo and $0.05 \mu \mathrm{g} /$ $\mathrm{kg} / \mathrm{min}$ remifentanil; group $\mathrm{RH}$ received a placebo and $0.3 \mu \mathrm{g} / \mathrm{kg} /$ min remifentanil; and group DRH received dexmedetomidine and $0.3 \mu \mathrm{g} / \mathrm{kg} / \mathrm{min}$ remifentanil.

Induction of anesthesia was commenced with a slow (30-60 s) intravenous (i.v.) bolus dose of remifentanil ( $1 \mu \mathrm{g} / \mathrm{kg}$ ), followed by propofol ( $1-2 \mathrm{mg} / \mathrm{kg})$; tracheal intubation was facilitated with rocuronium $(0.9 \mathrm{mg} / \mathrm{kg})$ in all groups. As mentioned above, infusion of dexmedetomidine or remifentanil in all groups was fixed, and anesthesia was maintained with desflurane and an oxygen/air mixture (fraction of oxygen, 50\%). When desflurane was required, its administration was started at the end-tidal concentration of 1 minimum alveolar concentration (MAC), and the concentration was adjusted by a $1 \%$ stepwise titration according to acceptable hemodynamic limits (mean arterial blood pressure between $-30 \%$ and $+15 \%$ and heart rate between $-40 \%$ and $+15 \%$ ) and to a target bispectral index (BIS) between 40 and 60 . Ephedrine $(20 \mathrm{mg})$ or atropine $(0.5 \mathrm{mg})$ was administered if a patient's preoperative baseline values went below the acceptable limits.

Upon completion of surgery, a neuromuscular blockade was reversed with pyridostigmine $(0.2 \mathrm{mg} / \mathrm{kg})$ and glycopyrrolate $(0.008 \mathrm{mg} / \mathrm{kg})$ when the train-of-four (TOF) ratio had returned to $25 \%$. When BIS values reached 80 and spontaneous breathing was achieved, extubation was performed. Dexmedetomidine or remifentanil infusion was discontinued when the final surgical stitch had been placed. Each patient was administered analgesics using a PCA pump containing morphine (60 mg), ketorolac (150 mg), and ramosetron $(0.6 \mathrm{mg})$ in a total volume of $100 \mathrm{ml}$ of saline. This device was set to deliver a basal infusion of $2 \mathrm{ml} / \mathrm{hr}$ and bolus doses of $0.5 \mathrm{ml}$ with a $15 \mathrm{~min}$ lockout period. Postoperative pain intensity was documented using a $100 \mathrm{~mm}$ linear VAS. The VAS consisted of a straight line with the left end of the line representing no pain and the right end of the line representing the worst pain. Patients were asked to mark the position on the line corresponding to their perception of pain. An i.v. dose of ketorolac (30 mg) was administered if patients reported a VAS score $\geq 40$, and $15 \mathrm{mg}$ ketorolac was 
added as needed during their postanesthesia care unit (PACU) stay.

The mechanical hyperalgesia threshold was measured preoperatively and $24 \mathrm{hr}$ after surgery using Von Frey filaments (Bioseb $^{\mathrm{TM}}$, Chaville, France) on peri-incisional areas, $2 \mathrm{~cm}$ above from the perpendicular line of the optical port site. This device consists of 20 monofilaments of constant length with a stepwise progression of diameters. The numerical grade of the filaments (1.65-6.65) corresponds to a logarithmic function of the equivalent forces of $0.008-300 \mathrm{~g}$. When the tip of a fiber of given length and diameter is pressed against a test area at a right angle, the applied force increases as the researcher continues to advance the probe, until the fiber bends. After the fiber bends, further advancement of the probe may induce more bending, but does not apply more force to the test area. This makes it possible to apply reproducible forces within a wide tolerance range to the tested surface. The force is continuously applied for $1 \mathrm{~s}$ and then removed. Subjects are instructed to respond "yes" to indicate that contact was felt during the stimulation or "no" to indicate that contact was not felt during the stimulation. If the subject reports a negative answer, a filament with a larger diameter is used and applied with increasing intensity until the subject reacts. The mechanical hyperalgesia threshold was defined as the lowest force $\left(\mathrm{g} / \mathrm{mm}^{2}\right)$ necessary to bend a Von Frey filament, which was perceived to be painful.

The primary endpoint was a mechanical hyperalgesia threshold at $24 \mathrm{hr}$ after surgery. Secondary endpoints were the time to the first postoperative analgesic requirement, postoperative pain intensity using VAS, and cumulative volume of a
PCA containing morphine over $24 \mathrm{hr}$. Side effects related to the study drugs included hypotension, bradycardia, dysrhythmia, shivering, and postoperative nausea and vomiting (PONV). Shivering was treated using a forced-air warming blanket. Nausea or vomiting was treated with i.v. ondansetron (4 mg).

A preliminary investigation showed that the means of the three treatment groups (group $\mathrm{C}$, group $\mathrm{RH}$, and group $\mathrm{DRH}$ ) for mechanical hyperalgesia threshold after surgery were 132, 84 , and $116 \mathrm{~g} / \mathrm{mm}^{2}$, respectively, with effect size of 0.37 and a standard deviation among subjects of $39.55 \mathrm{~g} / \mathrm{mm}^{2}$. Thus, a sample size of 26 patients per group was needed to demonstrate a significant difference with a power of $80 \%$ and an $\alpha$-coefficient of 0.05 . Assuming a $10 \%$ dropout rate, the final sample size was determined to be 30 patients per group. The results are presented as mean \pm SD or number (percentage) of patients. Comparisons of age, body weight, \% volume of desflurane, duration of anesthesia, mechanical hyperalgesia threshold, time to first postoperative analgesic requirement, pain intensity, and cumulative PCA volume over $24 \mathrm{hr}$ after surgery among the groups were conducted using one-way ANOVA. Post-hoc comparisons were performed with Bonferroni correction of the significance level. Chi-square tests were used to analyze categorical data, such as hypotension, bradycardia, shivering, dysrhythmia, and PONV. $\mathrm{P}<0.05$ was considered statistically significant.

\section{Results}

A total of 90 patients were assessed for eligibility and received

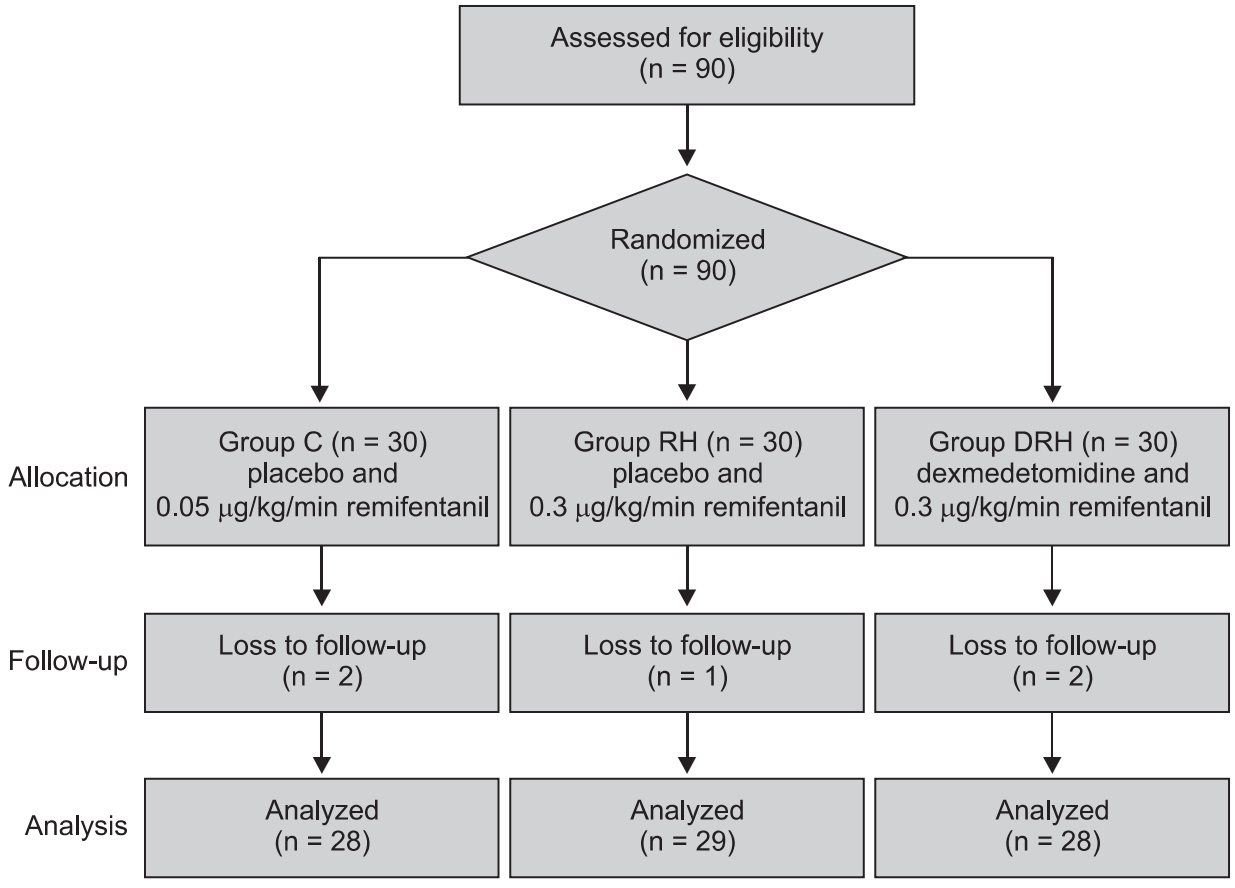

Fig. 1. The COSORT flowchart. 
Table 1. Demographic and Anesthetic Data

\begin{tabular}{lccc}
\hline & $\begin{array}{c}\text { Group C } \\
(\mathrm{n}=28)\end{array}$ & $\begin{array}{c}\text { Group RH } \\
(\mathrm{n}=29)\end{array}$ & $\begin{array}{c}\text { Group DRH } \\
(\mathrm{n}=28)\end{array}$ \\
\hline Age $(\mathrm{yr})$ & $49.6 \pm 6.6$ & $48.4 \pm 5.3$ & $49.0 \pm 6.4$ \\
Weight $(\mathrm{kg})$ & $58.9 \pm 4.1$ & $58.7 \pm 3.5$ & $59.2 \pm 3.9$ \\
Duration of anesthesia (min) & $139.5 \pm 12.4$ & $141.6 \pm 15.7$ & $141.3 \pm 15.4$ \\
Extubation time after surgery (min) & $16.3 \pm 3.8^{*}$ & $13.10 \pm 3.4$ & $13.8 \pm 3.2$ \\
Infusion of fluid (ml) & $1,107.1 \pm 174.1$ & $1,141.4 \pm 129.6$ & $1,096.4 \pm 145.3$ \\
Mean volume of desflurane (\%) & $7.3 \pm 0.7^{*}$ & $4.4 \pm 0.7^{\dagger}$ & $3.7 \pm 0.7$ \\
Tympanic temperature immediately after intubation $\left({ }^{\circ} \mathrm{C}\right)$ & $36.6 \pm 0.1$ & $36.6 \pm 0.1$ & $36.6 \pm 0.1$ \\
Tympanic temperature just before extubation $\left({ }^{\circ} \mathrm{C}\right)$ & $36.1 \pm 0.3$ & $36.1 \pm 0.3$ & $36.1 \pm 0.3$ \\
\hline
\end{tabular}

Values are expressed as mean \pm SD. Group C: placebo and $0.05 \mu \mathrm{g} / \mathrm{kg} / \mathrm{min}$ remifentanil, group RH: placebo and $0.3 \mu \mathrm{g} / \mathrm{kg} / \mathrm{min} \mathrm{remifentanil}$, and group DRH: dexmedetomidine and $0.3 \mu \mathrm{g} / \mathrm{kg} / \mathrm{min}$ remifentanil. ${ }^{*} \mathrm{P}<0.05$ versus the other 2 groups. ${ }^{\dagger} \mathrm{P}<0.05$ versus group DRH.

Table 2. Clinically Relevant Pain and Mechanical Hyperalgesia Threshold

\begin{tabular}{lccc}
\hline & $\begin{array}{c}\text { Group C } \\
(\mathrm{n}=28)\end{array}$ & $\begin{array}{c}\text { Group RH } \\
(\mathrm{n}=29)\end{array}$ & $\begin{array}{c}\text { Group DRH } \\
(\mathrm{n}=28)\end{array}$ \\
\hline Time to first postoperative analgesic requirement $(\mathrm{min})$ & $37.5 \pm 10.7$ & $28.3 \pm 8.3^{*}$ & $40.3 \pm 8.3$ \\
Analgesic consumption (ketorolac) during their PACU stay $(\mathrm{mg})$ & $33.3 \pm 6.2$ & $37.8 \pm 7.6^{*}$ & $31.7 \pm 4.9$ \\
Pain intensity & & & \\
VAS 1 hr after surgery & $52.1 \pm 11.0$ & $63.8 \pm 11.8^{*}$ & $46.4 \pm 8.7$ \\
VAS 6 hr after surgery & $41.8 \pm 9.1$ & $48.6 \pm 7.9^{*}$ & $41.3 \pm 7.2$ \\
VAS 12 hr after surgery & $31.1 \pm 9.2$ & $37.2 \pm 9.6^{*}$ & $25.7 \pm 6.3$ \\
VAS 24 hr after surgery & $19.6 \pm 7.4$ & $22.8 \pm 7.5^{\dagger}$ & $16.4 \pm 6.2$ \\
Preoperative mechanical hyperalgesia threshold $\left(\mathrm{g} / \mathrm{mm}^{2}\right)$ & $196.0 \pm 41.5$ & $196.6 \pm 42.1$ & $195.5 \pm 40.9$ \\
Mechanical hyperalgesia threshold at 24 hr after surgery $\left(\mathrm{g} / \mathrm{mm}^{2}\right)$ & $128.6 \pm 47.3$ & $89.0 \pm 36.9^{*}$ & $120.0 \pm 40$ \\
Cumulative PCA volume containing morphine $(\mathrm{ml})$ for $24 \mathrm{hr}$ after surgery & $58.3 \pm 2.6$ & $60.0 \pm 2.3^{*}$ & $57.9 \pm 1.8$ \\
\hline
\end{tabular}

Values are expressed as mean \pm SD. PACU: postanesthesia care unit. Group C: placebo and $0.05 \mu \mathrm{g} / \mathrm{kg} / \mathrm{min}$ remifentanil, group RH: placebo and $0.3 \mu \mathrm{g} / \mathrm{kg} / \mathrm{min}$ remifentanil, and group DRH: dexmedetomidine and $0.3 \mu \mathrm{g} / \mathrm{kg} / \mathrm{min}$ remifentanil. $* \mathrm{P}<0.05$ versus the other 2 groups. ${ }^{\dagger} \mathrm{P}<0.05$ versus group DRH.

Table 3. Postoperative Side Effects

\begin{tabular}{lccc}
\hline & $\begin{array}{c}\text { Group C } \\
(\mathrm{n}=28)\end{array}$ & $\begin{array}{c}\text { Group RH } \\
(\mathrm{n}=29)\end{array}$ & $\begin{array}{c}\text { Group DRH } \\
(\mathrm{n}=28)\end{array}$ \\
\hline Hypotension & $1(3.6)$ & $3(10.3)$ & $10(35.7)^{*}$ \\
Bradycardia & $1(3.6)$ & $4(13.8)$ & $11(39.3)^{*}$ \\
Dysrhythmia & $1(3.6)$ & $1(3.4)$ & $3(10.7)$ \\
Shivering & $9(32.1)$ & $17(58.6)^{\dagger}$ & $2(7.1)^{*}$ \\
PONV & $15(53.6)$ & $8(27.6)$ & $1(3.6)$ \\
\hline
\end{tabular}

Values are expressed as numbers (\%). PONV: postoperative nausea and vomiting. Group C: placebo and $0.05 \mu \mathrm{g} / \mathrm{kg} / \mathrm{min}$ remifentanil, group RH: placebo and $0.3 \mu \mathrm{g} / \mathrm{kg} / \mathrm{min}$ remifentanil, and group DRH: dexmedetomidine and $0.3 \mu \mathrm{g} / \mathrm{kg} / \mathrm{min}$ remifentanil. ${ }^{*} \mathrm{P}<0.05$ versus group the other 2 groups. ${ }^{\dagger} \mathrm{P}<0.05$ versus group $\mathrm{C}$.

study medication after randomization. Five of the 90 patients initially enrolled were withdrawn because of conversion to open surgery or re-exploration for postoperative bleeding (Fig. 1).

There were no significant differences between the three groups with respect to age, weight, duration of anesthesia, or perioperative tympanic temperature. Extubation time after surgery was significantly longer in group $\mathrm{C}$ than in the other two groups. The \% volume of desflurane was significantly higher in group $\mathrm{C}$ than in the other two groups, and that in group $\mathrm{DRH}$ was significantly lower than in group RH (Table 1).

The time to first postoperative analgesic requirement was significantly shorter in group RH than in the other two groups. Analgesic consumption (ketorolac) during PACU stay was significantly higher in group $\mathrm{C}$ than in the other two groups. Pain intensity using VAS was significantly greater in group $\mathrm{RH}$ than in group DRH and group C at $24 \mathrm{hr}$ and $12 \mathrm{hr}$ after surgery, respectively. The preoperative mechanical hyperalgesia threshold was not significantly different between the three groups. The mechanical hyperalgesia threshold around the surgical incision $24 \mathrm{hr}$ after surgery was significantly lower in group $\mathrm{RH}$ than in the other two groups. The volume of PCA containing morphine was significantly greater in group $\mathrm{RH}$ than in the other two groups (Table 2).

The frequency of hypotension and bradycardia was significantly higher in group DRH than in the other two groups. Postanesthetic shivering was significantly lower in group DRH than in the other two groups, and that in group $\mathrm{RH}$ was significantly higher than in group C. PONV was significantly lower in group $\mathrm{DRH}$ than in the other two groups, and that in group $\mathrm{C}$ was 
significantly higher than in group RH (Table 3).

\section{Discussion}

The major finding of this study was that dexmedetomidine (two-step infusion; an initial dose of $1.0 \mu \mathrm{g} / \mathrm{kg}$ for $10 \mathrm{~min}$, followed by a continuous infusion of $0.7 \mu \mathrm{g} / \mathrm{kg} / \mathrm{h}$ ) attenuated high-dose remifentanil-induced hyperalgesia in patients undergoing LAVH.

$\mathrm{OIH}$ is characterized by a paradoxical increase in pain intensity, distribution, or sensitivity in patients receiving highdoses or long durations of opioids for the treatment of pain [7]. As a result, patients become more sensitive to certain painful stimuli. However, epidemiologic reports regarding the incidence or prevalence of $\mathrm{OIH}$ are limited. Although the precise molecular mechanism of $\mathrm{OIH}$ is not yet understood, acute receptor desensitization via uncoupling of the receptor from G-proteins, up-regulation of the cAMP pathway, activation of the $N$-methyl-D-aspartate (NMDA)-receptor system, and descending facilitation have been proposed to be involved. Of these, the central NMDA system is considered the most likely player. NMDA receptors are comprised of two types of subunits: the principal subunit NR1 and the modulatory subunit NR2A-D. Particularly crucial is the NMDA receptor 2B (NR2B) subunit, which plays an important role in spinal dorsal horn sensory pathways $[10,11]$.

In the present study, we found that intraoperative high-dose remifentanil induced a decreased mechanical hyperalgesia threshold, enhanced pain intensity, shorter time to first postoperative analgesic requirement, and greater morphine consumption, all indicative of OIH. Enhanced tyrosine phosphorylation of NR2B in the spinal cord is associated with remifentanil-induced postoperative hyperalgesia. In fact, it plays a key role in the NMDA receptor activation, and contributes to nociceptor activity-induced spinal plasticity and the development of central sensitization that leads to $\mathrm{OIH}$ [12]. Strategies for preventing, reversing, or managing $\mathrm{OIH}$ have been attempted. These include the NMDA receptor antagonists ketamine $[1,12]$ or magnesium [9], the GABA receptor antagonist propofol [8], the $\alpha 2$ agonists clonidine [1] or dexmedetomidine [2,3,5], the $\beta$-blocker propranolol [13], and the COX-2 inhibitor parecoxib [14].

Dexmedetomidine, a highly selective and potent $\alpha 2$ adrenergic receptor agonist attenuates high-dose remifentanil-induced hyperalgesia by decreasing spinal tyrosine phosphorylation of the NR2B subunit [3]. As mentioned above, in the present study, the dexmedetomidine (group DRH) alleviated clinically relevant pain by relieving symptoms such as enhanced pain intensity, inducing a shorter time to first postoperative analgesic requirement and high morphine consumption; mechanically evoked pain up to $24 \mathrm{hr}$ after surgery was also alleviated. It has been shown that the effect of dexmedetomidine on the cumulative consumption of morphine persisted for $24 \mathrm{hr}$, and its effect on postoperative pain intensity for $48 \mathrm{hr}$, as compared to controls [15].

$\alpha 2$ adrenergic receptor agonists with sedation properties have been shown to decrease anesthetic requirements in animal models $[16,17]$ and human clinical trials $[18,19]$. The locus ceruleus of the brainstem is the major site of the hypnotic action of $\alpha 2$ adrenergic receptor agonists, which cause a reduction in noradrenergic activity. In addition to synaptic noradrenergic depletion, the mechanism of the hypnotic action of $\alpha 2$ adrenergic receptor agonists can be explained by the fact that $\alpha 2$ adrenergic receptor agonists and general anesthetics increase $\mathrm{K}^{+}$efflux through the neuronal cell membrane and reduce intracellular cyclic adenosine monophosphate (cAMP), which in turn induces changes in transmembrane hyperpolarization of excitable neuronal cells $[20,21]$. In the present study, the dexmedetomidine (group DRH) significantly reduced the desflurane requirement for anesthetic maintenance by $49 \%$, and $16 \%$ compared with the groups receiving placebo concomitant with low- or high-dose remifentanil (groups $\mathrm{C}$ and $\mathrm{RH}$, respectively). Our data correspond with some studies showing that dexmedetomidine diminished anesthetic requirements by $30-90 \%[22,23]$.

Tufanogullari et al. [24] reported that although dexmedetomidine showed better early recovery (e.g., PACU stay), later recovery events (e.g., hospital discharge, resumption of oral intake and bowel function) were similar as compared to controls. In the present study, time to extubation in group DRH (dexmedetomidine and high-dose remifentanil) was significantly shorter than in group C (placebo and low-dose remifentanil) but not significantly different from time to extubation in group $\mathrm{RH}$ (placebo and high-dose remifentanil). As mentioned above, the significant difference in desflurane requirements between group DRH and group C might have affected time to extubation. However, more data are necessary to confirm the effect of dexmedetomidine on time to extubation.

The hemodynamic effects of $\alpha 2$ adrenergic receptor agonists may be explained through a reduction of sympathetic tone. A decreased sympathetic activity results in lower blood pressure and reduced heart rate [25]. Because high catecholamine concentrations may trigger PONV, the antiemetic effect of $\alpha 2$ adrenergic receptor agonists may result from a decreased sympathetic activity [26]. In the present study, we found that the frequency of hypotension and bradycardia in group DRH was significantly higher, and PONV was significantly lower, as compared to the other two groups. However, dexmedetomidine combined with high-doses of remifentanil should be used cautiously, as this present study showed that patient's preoperative hemodynamic baseline values in group DRH significantly went 
below the acceptable limits compared to the two groups.

Postanesthetic shivering or $\mathrm{OIH}$ is associated with highdose remifentanil and may be prevented by NMDA receptor antagonists [27]. The antishivering action of dexmedetomidine results from lowering vasoconstriction and shivering thresholds [28]. In the present study, we found that OIH and shivering induced by high-dose remifentanil were alleviated by dexmedetomidine. The findings of the present study provide an indirect support to the fact that antihyperalgesic and antishivering effects of $\alpha 2$ adrenergic receptor agonists are associated with NMDA receptors.

In conclusion, high-doses of remifentanil induced hyperalgesia, which presented a decreased mechanical hyperalgesia threshold, enhanced pain intensity, shorter time to first postoperative analgesic requirement, and greater morphine consumption. A two-step dexmedetomidine infusion efficiently alleviated $\mathrm{OIH}$ symptoms. Therefore, dexmedetomidine may be a novel and effective treatment option for preventing or attenuating OIH. Further studies are required to investigate the use of dexmedetomidine as part of a multimodal approach for $\mathrm{OIH}$.

\section{Acknowledgments}

This study was supported by Wonkwang University in 2012.

\section{References}

1. Virtanen R, Savola JM, Saano V, Nyman L. Characterization of the selectivity, specificity and potency of medetomidine as an alpha 2-adrenoceptor agonist. Eur J Pharmacol 1988; 150: 9-14.

2. Belgrade M, Hall S. Dexmedetomidine infusion for the management of opioid-induced hyperalgesia. Pain Med 2010; 11: 1819-26.

3. Koppert W, Sittl R, Scheuber K, Alsheimer M, Schmelz M, Schuttler J. Differential modulation of remifentanil-induced analgesia and postinfusion hyperalgesia by S-ketamine and clonidine in humans. Anesthesiology 2003; 99: 152-9.

4. Zhang WS, Xu H, Xu B, Sun S, Deng XM, Zhang YQ. Antihyperalgesic effect of systemic dexmedetomidine and gabapentin in a rat model of monoarthritis. Brain Res 2009; 1264: 57-66.

5. Zheng Y, Cui S, Liu Y, Zhang J, Zhang W, Zhang J, et al. Dexmedetomidine prevents remifentanil-induced postoperative hyperalgesia and decreases spinal tyrosine phosphorylation of N-methyl-daspartate receptor 2B subunit. Brain Res Bull 2012; 87: 427-31.

6. Bürkle H, Dunbar S, Van Aken H. Remifentanil: a novel, shortacting, mu-opioid. Anesth Analg 1996; 83: 646-51.

7. Chu LF, Angst MS, Clark D. Opioid-induced hyperalgesia in humans: molecular mechanisms and clinical considerations. Clin J Pain 2008; 24: 479-96.

8. Singler B, Tröster A, Manering N, Schüttler J, Koppert W. Modulation of remifentanil-induced postinfusion hyperalgesia by propofol. Anesth Analg 2007; 104: 1397-403.
9. Lee C, Song YK, Jeong HM, Park SN. The effects of magnesium sulfate infiltration on perioperative opioid consumption and opioid-induced hyperalgesia in patients undergoing robot-assisted laparoscopic prostatectomy with remifentanil-based anesthesia. Korean J Anesthesiol 2011; 61: 244-50.

10. Mori H, Mishina M. Structure and function of the NMDA receptor channel. Neuropharmacology 1995; 34: 1219-37.

11. Boyce S, Wyatt A, Webb JK, O'Donnell R, Mason G, Rigby M, et al. Selective NMDA NR2B antagonists induce antinociception without motor dysfunction: correlation with restricted localisation of NR2B subunit in dorsal horn. Neuropharmacology 1999; 38: 611-23.

12. Gu X, Wu X, Liu Y, Cui S, Ma Z. Tyrosine phosphorylation of the $\mathrm{N}$-Methyl-D-Aspartate receptor 2B subunit in spinal cord contributes to remifentanil-induced postoperative hyperalgesia: the preventive effect of ketamine. Mol Pain 2009; $5: 76$.

13. Chu LF, Cun T, Ngai LK, Kim JE, Zamora AK, Young CA, et al. Modulation of remifentanil-induced postinfusion hyperalgesia by the $\beta$-blocker propranolol in humans. Pain 2012; 153: 974-81.

14. Tröster A, Sittl R, Singler B, Schmelz M, Schüttler J, Koppert W. Modulation of remifentanil-induced analgesia and postinfusion hyperalgesia by parecoxib in humans. Anesthesiology 2006; 105: 1016-23.

15. Blaudszun G, Lysakowski C, Elia N, Tramèr MR. Effect of perioperative systemic $\alpha 2$ agonists on postoperative morphine consumption and pain intensity: systematic review and meta-analysis of randomized controlled trials. Anesthesiology 2012; 116: 1312-22.

16. Maze M, Birch B, Vickery RG. Clonidine reduces halothane MAC in rats. Anesthesiology 1987; 67: 868-9.

17. Segal IS, Vickery RG, Walton JK, Doze VA, Maze M. Dexmedetomidine diminishes halothane anesthetic requirements in rats through a postsynaptic alpha 2 adrenergic receptor. Anesthesiology 1988; 69: 818-23.

18. Aantaa R, Jaakola ML, Kallio A, Kanto J. Reduction of the minimum alveolar concentration of isoflurane by dexmedetomidine. Anesthesiology 1997; 86: 1055-60.

19. Khan ZP, Munday IT, Jones RM, Thornton C, Mant TG, Amin D. Effects of dexmedetomidine on isoflurane requirements in healthy volunteers. 1: Pharmacodynamic and pharmacokinetic interactions. Br J Anaesth 1999; 83: 372-80.

20. Correa-Sales C, Rabin BC, Maze M. A hypnotic response to dexmedetomidine, an alpha 2 agonist, is mediated in the locus coeruleus in rats. Anesthesiology 1992; 76: 948-52.

21. Andrade R, Aghajanian GK. Opiate- and alpha 2-adrenoceptorinduced hyperpolarizations of locus ceruleus neurons in brain slices: reversal by cyclic adenosine 3':5'-monophosphate analogues. J Neurosci 1985; 5: 2359-64.

22. Aho M, Lehtinen AM, Erkola O, Kallio A, Korttila K. The effect of intravenously administered dexmedetomidine on perioperative hemodynamics and isoflurane requirements in patients undergoing abdominal hysterectomy. Anesthesiology 1991; 74: 997-1002.

23. Aho M, Erkola O, Kallio A, Scheinin H, Korttila K. Dexmedetomidine infusion for maintenance of anesthesia in patients undergoing abdominal hysterectomy. Anesth Analg 1992; 75: 940-6.

24. Tufanogullari B, White PF, Peixoto MP, Kianpour D, Lacour T, Griffin J, et al. Dexmedetomidine infusion during laparoscopic bariatric surgery: The effect on recovery outcome variables. Anesth 
Analg 2008; 106: 1741-8.

25. Bloor BC, Ward DS, Belleville JP, Maze M. Effects of intravenous dexmedetomidine in humans. II. Hemodynamic changes. Anesthesiology 1992; 77: 1134-42.

26. Watcha MF, White PF. Postoperative nausea and vomiting. Its etiology, treatment, and prevention. Anesthesiology 1992; 77: 16284.
27. Komatsu R, Turan AM, Orhan-Sungur M, McGuire J, Radke OC, Apfel CC. Remifentanil for general anaesthesia: a systematic review. Anaesthesia 2007; 62: 1266-80.

28. Bajwa SJ, Gupta S, Kaur J, Singh A, Parmar S. Reduction in the incidence of shivering with perioperative dexmedetomidine: a randomized prospective study. J Anaesthesiol Clin Pharmacol 2012; 28: 86-91. 